\title{
Apuntes para el estudio del consumo en clave histórica
}

\author{
Notes for the study of consumption in a historical key
}

Inés Pérez

Consejo Nacional de Investigaciones Científicas y Técnicas

Centro de Estudios Históricos

Universidad Nacional de Mar del Plata

(Argentina)

inesp18@yahoo.com

En los últimos años se ha renovado el interés (8) por la historia del consumo en Argentina y en América Latina. Recientemente, diversas investigaciones han mostrado la relevancia del consumo para el análisis de distintas transformaciones sociales que exceden lo estrictamente económico, e involucran desde la reorganización de las identidades sociales, al mundo de la política y la vida cívica, pasando por las relaciones familiares y la intimidad. ${ }^{1} \mathrm{La}$

1. Para la Argentina, ver, por ejemplo, LLUCH, Andrea, Las manos visibles del mercado: Intermediarios $y$ consumidores en la Argentina (Siglos XIX y XX), Prohistoria, Rosario, 2015; MILANESIO, Natalia, Cuando los trabajadores salieron de compras: nuevos consumidores, publicidad y cambio cultural durante el primer peronismo, Siglo XXI, Buenos Aires, 2014; PIGLIA, Melina, Autos, rutas y turismo: el automóvil club argentino y el estado, Siglo XXI, Buenos Aires, 2014; MANZANO, Valeria, The Age of Youth in Argentina: Culture, Politics, and Sexuality from Perón to Videla, The University of North Carolina Press, 2014; PITE, Rebekah, Creating a common table in twentieth-century Argentina: Doña Petrona, Women and Food, The University of North Carolina Press, 2013; KARUSH, Matthew, Cultura de clase. Radio $y$ cine en la creación de una Argentina dividida (19201946), Ariel, Buenos Aires, 2013; PÉREZ, Inés, El hogar tecnificado: familias, género y vida cotidiana, Biblos, Buenos Aires, 2012; ELENA, Eduardo, Dignifying Argentina: Peronism, Citizenship, and Mass Consumption, University of Pittsburgh Press, 2011; FERNÁNDEZ, Sandra, La revista EL Círculo o el arte de papel Una experiencia editorial en la Argentina del Centenario, Universidad de Murcia, Murcia, 2010; COSSE, Isabella, Mafalda: bistoria 
mirada sobre el consumo ha generado nuevas preguntas en áreas como la historia social, los estudios sobre la clase media y trabajadora, la historia de las empresas, la de las industrias culturales y los estudios de género.

A pesar de este desarrollo, las investigaciones sobre la historia del consumo aún son escasas y no existe un campo específico de estudios identificados con este concepto. A diferencia de lo que ocurre con otras áreas, no hay jornadas o publicaciones específicas sobre consumo y existen pocas mesas temáticas dedicadas al tema en jornadas o congresos más generales que, además, son muy recientes. En parte esto responde a la relativa novedad del abordaje historiográfico del consumo en relación al observado en otros escenarios. $\mathrm{Si}$ en Europa y Estados Unidos la historia del consumo comenzó a ganar fuerza en los años ochenta $^{2}$, en Argentina, en cambio, el interés

social y política, Fondo de Cultura Económica, Buenos Aires, 2010; CALDO, Paula, Mujeres cocineras. Hacia una historia sociocultural de la cocina, Argentina a fines del siglo XIX y primera mitad del XX, Prohistoria, Rosario, 2009; REMEDI, Fernando, Dime qué comes y cómo lo comes y te diré quién eres. Una historia social del consumo alimenario en la modernización argentina. Córdoba, 18701930, Centro de Estudios Históricos "Prof. Carlos S. A. Segreti”, Córdoba, 2006; PÉREZ, Inés y RIBEIRO DOS SANTOS, Marinês (editoras) Gênero e consumo: representaçôes midiáticas de práticas de consumo no espaço doméstico (Argentina e Brasil no Século XX), UFPR Editora, Curitiba, (en prensa).

2. E1 trabajo de Neil McKendrick publicado hacia mediados de los setenta ha sido señalado como un puntapié para el desarrollo de las investigaciones sobre consumo que se multiplicarían durante los años ochenta. Ver MCKENDRICK, Neil, "Home demand and economic growth: a new view of the role of women and children in the industrial revolution", en MCKENDRICK, Neil (editor) Historical Perspectives: Studies in English Thought and Society in Honour of J. H. Plum, Hutchison, London, 1974; MCKENDRICK, Neil, BREWER, John y PLUMB, John Harold, The Birth of 98 sobre estos temas sólo comenzó a cristalizarse hacia fines de los años noventa. ${ }^{3}$

En el ámbito de la historiografía europea y norteamericana, se han señalado dos líneas en las aproximaciones al consumo. ${ }^{4} \mathrm{La}$ primera, más cercana a la historia económica y social, se centró en la pregunta por la existencia y la amplitud de mercados de consumo masivos, y dio relevancia al estudio de patrones de consumo de distintos tipos de bienes (como alimentos, tabaco, vestido, bienes durables) a partir del análisis de inventarios. ${ }^{5} \mathrm{La}$ segunda, en cambio, más cercana a la historia cultural, destacó los significados asignados a aquello

a Consumer Society: The Commercialization of Eighteenth Century England, Hutchison, London, 1982.

3. ROCCHI, Fernando, "Consumir es un placer: la industria y la expansión de la demanda en Buenos Aires a la vuelta del siglo pasado", en Desarrollo Económico, V. 37, No 148, 1998, pp. 533-558; ROCCHI, Fernando, "Inventando la soberanía del consumidor: publicidad, privacidad y revolución del mercado en la Argentina (1860-1940)", en DEVOTO, Fernando y MADERO, Marta (compiladores) Historia de la vida privada en la Argentina, Taurus, Buenos Aires, 1999, pp. 201-322; ROCCHI, Fernando, "La americanización del consumo: las batallas por el mercado argentino, 1920-1945”, en BARBERO, María I. y REGALSKY, Andrés M. (editores) Estados Unidos y América Latina en el siglo XX. Transferencias económicas, tecnológicas y culturales, UNTREF, Buenos Aires, 2003, pp. 131-189; ROCCHI, Fernando, Chimneys in the Desert. Industrialization in Argentina during the Export Boom Years, 1870-1930, Stanford University Press, 2006.

4. GLENNIE, Paul, “Consumption within Historical Studies”, en MILLER, Daniel (editor) Acknowledging Consumption: A Review of Studies, Routledge, London and New York, 1995.

5. Ver como ejemplos: SHAMMAS, Carole, "Changes in English and Anglo-American consumption from 15501800", en BREWER, John y PORTER, Roy (editores) Consumption and the World of Goods, Routledge, London, 1993, pp. 177-205; MENNELL, Stephen, All Manners of Food: Eating and Taste in England and France from the Middle Ages to the Present, Blackwell, Oxford, 1985. 
que se consumía. ${ }^{6}$ Más recientemente, otras líneas de análisis también ganaron relevancia, dentro de las que se destaca el estudio de instituciones, medios de comunicación y publicidades, así como el cruce de la historia del consumo con la historia política, en el que la figura del "ciudadano consumidor" ocupó un sitio central. ${ }^{7}$ Por otro lado, los estudios de género tuvieron un peso considerable en el desarrollo de la historia del consumo, atravesando las líneas señaladas antes. ${ }^{8}$

6. Ver, por ejemplo, CAMPBELL, Colin, "Understanding traditional and modern patterns of consumption in eighteenth century England: a characteraction approach", en BREWER, John and PORTER, Roy (editores) Consumption and..., Op. Cit., pp. 4057; HOROWITZ, Daniel, The Morality of Spending: Attitudes toward the Consumer Society in America, 18751940, Johns Hopkins University Press, Baltimore, 1985.

7. Ver, por ejemplo, SCANLON, Jennifer, Inarticulate Longings: The Ladies' Home Journal, Gender and the Promises of Consumer Culture, Routledge, Londres y Nueva York, 1995; COHEN, Lizabeth, A Consumers' Republic: The Politics of Mass Consumption in Postwar America, Vintage Books, Nueva York, 2003; SMART, Judith, “The Politics of Consumption: The Housewives' Associations in South-eastern Australia Before 1950", en Journal of Women's History, New York, 2006, V. XVIII, No 3, pp. 13-39; STORRS, Landon, "Left-Feminism, the Consumer Movement, and Red Scare Politics in the United States, 1935-1960", en Journal of Women's History, New York, 2006, V. XVIII, No 3, pp. 40-67; PULJU, Rebecca, "Consumers for the Nation: Women, Politics, and Consumer Organization in France, 1944-1965", en Journal of Women's History, New York, 2006, V. XVIII, No 3, pp. 68-90; MILANESIO, Natalia, "The Guardian Angels of the Domestic Economy”: Housewives' Responsible Consumption in Peronist Argentina", en Journal of Women's History, New York, 2006, V. XVIII, No 3, pp. 91-117.

8. Ver, por ejemplo, DAVIDOFF, Leonore y HALL, Catherine, Family Fortunes: Men and Women of the English Middle Class, Hutchison, London, 1987; HOROWITZ, Roger y MOHUN, Arwen (editores) His and Hers: Gender, Consumption and Technology, University Press of Virginia, Charlottesville and London, 1998; SCANLON, Jennifer (editora) The Gender and Consumer
Sin embargo, incluso en Europa y Estados Unidos, donde las investigaciones sobre consumo son anteriores y mucho más abundantes que en el escenario local, la existencia de un "campo" propiamente dicho sobre la historia del consumo ha sido materia de debate. Como ha señalado Susan Strasser, el consumo puede ser pensado como un prisma a través del que se pueden ver distintos aspectos de la vida social. ${ }^{9}$ Esto ha llevado a una relativa dispersión de los estudios, que muchas veces hacen foco en discusiones que contribuyen a otros campos, informando la historia del consumo pero sin centrarse en él. ${ }^{10}$ Dicha dispersión, por otra parte, no es sólo temática, sino también disciplinar. No es casual que cuando en 2001, los editores

Culture Reader, New York University Press, Nueva York y Londres, 2000; EPP, Marlene, IACOVETTA, Franca y SWYRPA, Frances (editoras) Sisters or Strangers? Immigrant, Ethnic, and Racialized Women in Canadian History, University of Toronto Press, Toronto, 2004.

9. STRASSER, Susan, "Making Consumption Conspicuous: Transgressive Topics Go Mainstream”, en Technology and Culture, V. 43, 2002, p. 756.

10. En Argentina, ver por ejemplo, PASTORIZA, Elisa, Mar del Plata, la conformación de una ciudad turística de masas, UNMDP, Mar del Plata, 1993; TORRE, Juan Carlos y PASTORIZA, Elisa, "Mar del Plata el sueño de los argentinos", en DEVOTO, Fernando y MADERO, Marta (compiladores) Historia de la vida privada en la Argentina. La Argentina entre multitudes y soledades, de los años treinta a la actualidad. Buenos Aires, Taurus T. III, 1999, pp. 49-77; PASTORIZA, Elisa (editora) Las puertas al Mar. Consumo, ocio y politica en Mar del Plata, Montevideo y Viña del Mar, Biblos, Buenos Aires, 2002; TORRE, Juan Carlos y PASTORIZA, Elisa, "La democratización del bienestar", en Juan Carlos Torre (compilador) Los años peronistas, Sudamericana, Buenos Aires, 2002, pp. 257-312; NARI, Marcela y FEIJÓO, María del Carmen, "Women in Argentina during the 1960's”, en Latin American Perspectives, Riverside, 1996, V. 23, No 1, pp. 7-27; PUJOL, Sergio, La década rebelde. Los años 60 en la Argentina, Emecé, Buenos Aires2002; GAYOL, Sandra y MADERO, Marta (editoras) Formas de Historia Cultural. Prometeo, Buenos Aires, 2007. 
del Journal of Consumer Culture lanzaban esta nueva propuesta editorial, insistieran en que el estudio del consumo no sólo era interdisciplinar, sino que promovía la erosión de las fronteras disciplinares, invitando al diálogo a investigadores provenientes de la Historia, la Antropología, la Sociología, la Economía, los Estudios Culturales, los Estudios de Género. ${ }^{11}$

Ahora bien, ¿qué es "consumir”? Siguiendo a Colin Campbell podríamos decir que el consumo involucra no sólo la compra sino también la selección, el uso, el mantenimiento, la reparación y el descarte de un objeto. ${ }^{12}$ Por otro lado, no sólo se consumen objetos, sino también ideas y experiencias, deseos y expectativas. Como han mostrado aproximaciones pioneras como las de Mary Douglas y Baron Isherwood, un mismo objeto puede tener diferentes significados dependiendo del momento histórico, pero también del espacio geográfico, y de si quien lo consume es varón o mujer, de su edad y del grupo social al que pertenece. ${ }^{13}$ Consumir, en este sentido, excede la acción instrumental de satisfacer una necesidad, e implica también la construcción de identidades sociales, así como la búsqueda de pertenencia y de distinción social. ${ }^{14}$

11. RITZER, George y SLATER, Don, “Editorial”, en Journal of Consumer Culture, V. 1, № 1, 2001, pp. 5-8.

12. CAMPBELL, Colin, “The Sociology of

Consumption”, en MILLER, Daniel (editor)

Acknowledging Consumption..., Op. Cit., p. 102.

13. DOUGLAS, Mary y ISHERWOOD, Baron, The world of Goods, Basic Books, Nueva York, 1979;

APPADURAI, Arjun (editor) The social life of things.

Cambridge University Press, Cambridge, 1988;

MILLER, Daniel (editor) Acknowledging Consumption..., Op. Cit.

14. Al utilizar la noción de distinción, la referencia a Pierre Bourdieu es ineludible. Sin embargo, la noción
Retomando estas aproximaciones, este dossier busca contribuir a conformar un espacio de intercambio entre quienes se encuentran trabajando problemas que, de manera más o menos explícita, aportan al desarrollo de los estudios históricos del consumo. Los artículos que lo componen abordan cuestiones que van desde el consumo de nuevos objetos y discursos -como la muñeca y la revista Marilú-, al de nuevas experiencias -como la del viaje en avión-; del consumo como instancia para la intervención del Estado sobre la vida familiar, al consumo como instancia de legitimación de una política exterior. ${ }^{15}$

bourdiana ha sido objeto de numerosas críticas, entre ellas, la de adoptar una posición legitimista respecto de la cultura popular, es decir, en la que la cultura popular no tendría originalidad alguna sino que podría comprenderse acabadamente a partir de la práctica de la emulación. En este sentido, Claude Grignon y JeanClaude Passeron han propuesto un abordaje de la cultura popular a partir de un movimiento pendular entre una mirada legitimista y una populista (de acuerdo a la que la cultura popular es independiente de la cultura de la elite). En mi conceptualización intento seguir los parámetros observados por estos autores para dar cuenta de las tensiones entre distintos modelos y sus usos, apropiaciones y resignificaciones. Ver BOURDIEU, Pierre, La distinción. Criterios y bases sociales del gusto, Taurus, Madrid, 1998 (1979); DE CERTEAU, Michel, La invención de lo cotidiano. Artes de hacer, Universidad Iberoamericana, México, 1996; GRIGNON, Claude y PASSERON, Jean-Claude, Lo culto y lo popular. Miserabilismo y populismo en sociología y literatura, Nueva Visión, Buenos Aires, 1991.

15. Los artículos que componen el dossier han sido escritos por jóvenes investigadoras cuya producción previa ha sido de gran relevancia para el reciente desarrollo de los estudios sobre consumo. Ver, por ejemplo, PIGLIA, Melina, Autos, rutas..., Op. Cit.; PIGLIA, Melina, "Commercial Aviation in Argentina: A Call to Re-think the History of Aeromobility in Latin America", en T2M Yearbook 2015, (en prensa); PIGLIA, Melina, "El ACA e YPF entre las administraciones conservadoras y el peronismo. La red nacional de estaciones de servicio", en Boletin del Instituto de Historia Argentina y Americana “Dr. Emilio Ravignani”, Tercera Serie, No 37, 2013, pp. 
El primer artículo del dossier, a cargo de Paula Bontempo, busca historizar la figura del "niño-cliente" a partir del estudio de las estrategias comerciales para promover el consumo juguetes. En particular, analiza la promoción de la muñeca Marilú, deteniéndose en la publicación de una revista del mismo nombre destinada a un público de niñas, en la que no sólo se incentivaba la compra de este nuevo producto, sino que se enseñaba la forma "correcta" de utilizarlo. Este texto se inserta en las discusiones sobre historia de la infancia, poniendo el centro en el consumo a partir del que se definen modelos de comportamiento de género y clase.

Seguidamente, el artículo de Melina Piglia reconstruye las primeras experiencias de aviación comercial en la Argentina. Para ello, presenta las condiciones materiales en las que se desarrollaron esos primeros viajes, para luego trabajar sobre las experiencias y los cambios

143-173; PIGLIA, Melina, "En torno a los Parques Nacionales: primeras experiencias de una política turística nacional centralizada en la Argentina (19341950)", en PASOS, Revista de Turismo y Patrimonio, V. 10, No 1, 2012, pp. 61-73; BONTEMPO, Paula, "Los niños de Billiken. Las infancias en Buenos Aires en las primeras décadas del siglo veinte", en Anuario del Centro de Estudios Históricos Prof. Carlos S. A. Segreti, Córdoba, 2012, Año 12, No 12, pp. 201-221, BONTEMPO, Paula y QUEIROLO, Graciela, "Las "chicas modernas" se emplean como dactilógrafas: feminidad, moda y trabajo en Buenos Aires (1920-1930)", en Bicentenario. Revista de Historia de Chile y América, Santiago, 2012, V. II, No 2, pp. 51-76; BONTEMPO, Paula, "Para Ti: una revista moderna para una mujer moderna, 1922-1935”, en Estudios Sociales, Santa Fe, 2011, No 41, pp. 127146; AGUILAR, Paula Lucía, El hogar como problema y como solución. Una mirada genealógica de la domesticidad a través de las politicas sociales. Argentina 1890-1940, Ediciones del CCC, Buenos Aires, 2014; AGUILAR, Paula Lucía y GRONDONA, Ana, "Condiciones de vida obrera y marginalidad social. Un estudio arqueológico de los "saberes expertos de la pobreza", en Voces del Fénix, Buenos Aires, 2013, No 23, pp. 14-23. en las disposiciones corporales exigida a los pasajeros, y sobre las representaciones sociales del viaje en avión. De esta manera, Piglia dialoga con los estudios sobre la movilidad y el turismo, haciendo foco en una definición del consumo en la que tanto las prácticas, como los deseos y las expectativas resultan centrales.

El siguiente texto, de Paula Aguilar, analiza una encuesta realizada entre 1936 y 1937 por el Instituto Nacional de Nutrición, en colaboración con diversas instituciones, en la que se registraron los presupuestos y los gastos de 600 hogares de la ciudad de Buenos Aires. Aguilar examina dicha encuesta mostrando cómo el consumo, en particular el de alimentos, se constituyó en un elemento relevante en las políticas sociales sobre la pobreza a partir de la delimitación de un nivel mínimo de salarios para el desarrollo de una vida "saludable". A partir de la identificación del concepto "hogar" como una instancia para la intervención del Estado sobre la vida familiar, este artículo contribuye a los estudios del consumo obrero $\mathrm{y}$ de los sectores populares, relegados, en términos generales, por el estudio del consumo de las elites y los sectores medios.

Finalmente, el artículo de Lisa Ubelaker Andrade, observa la construcción de una imagen del Panamericanismo y de América Latina en la cultura popular estadounidense de los años cuarenta, que generó un cambio en el modo en el que los estadounidenses imaginaban su papel personal en la política exterior de su país. Dichas imágenes estuvieron ancladas en unas prácticas y un imaginario vinculados al consumo, como la compra de mercancías producidas en América Latina e identificadas con atributos latinoamericanos (la calidez, lo tradicional, lo natural, lo indígena), donde la "señora consumidora" tenía un rol de 
suma relevancia. En este sentido, el texto de Ubelaker Andrade articula dimensiones que habitualmente son abordadas por separado: la política exterior, la cultura popular, el consumo doméstico y el género.

Los artículos que conforman este dossier muestran caminos posibles para el abordaje del estudio del consumo en una clave histórica. Poniendo el acento en distintos elementos, muestran la relevancia de las preguntas sobre el consumo para la historia del Estado y las políticas públicas, la historia de las empresas, de la tecnología, la movilidad, la familia, el género, la infancia, etc. Por otro lado, mirados en conjunto, los textos muestran las potencialidades que surgen de poner en diálogo investigaciones originadas en campos específicos que, al cambiar el foco hacia el consumo, generan nuevos interrogantes y perspectivas de análisis.<smiles>C=CC=[Te]=CC</smiles> 


\section{Bibliografía}

AGUILAR, Paula Lucía y GRONDONA, Ana, "Condiciones de vida obrera y marginalidad social. Un estudio arqueológico de los "saberes expertos de la pobreza", en Voces del Fénix, Buenos Aires, 2013, No 23 , pp. 14-23.

AGUILAR, Paula Lucía, El hogar como problema y como solución. Una mirada genealógica de la domesticidad a través de las politicas sociales. Argentina 1890-1940, Ediciones del CCC, Buenos Aires, 2014.

APPADURAI, Arjun (editor) The social life of things. Cambridge University Press, Cambridge, 1988.

BONTEMPO, Paula, "Para Ti: una revista moderna para una mujer moderna, 1922-1935", en Estudios Sociales, Santa Fe, 2011, No 41, pp. 127-146.

BONTEMPO, Paula, "Los niños de Billiken. Las infancias en Buenos Aires en las primeras décadas del siglo veinte", en Anuario del Centro de Estudios Históricos Prof. Carlos S. A. Segreti, Córdoba, 2012, Año 12, No 12, pp. 201-221.

BONTEMPO, Paula y QUEIROLO, Graciela, "Las “chicas modernas” se emplean como dactilógrafas: feminidad, moda y trabajo en Buenos Aires (1920-1930)", en Bicentenario. Revista de Historia de Chile y América, Santiago, 2012, V. II, No 2, pp. 51-76.

BOURDIEU, Pierre, La distinción. Criterios y bases sociales del gusto, Taurus, Madrid, 1998 (1979).

DE CERTEAU, Michel, La invención de lo cotidiano. Artes de hacer, Universidad Iberoamericana, México, 1996.

CALDO, Paula, Mujeres cocineras. Hacia una historia sociocultural de la cocina, Argentina a fines del siglo XIX y primera mitad del XX, Prohistoria, Rosario, 2009.

CAMPBELL, Colin, "Understanding traditional and modern patterns of consumption in eighteenth century England: a character-action approach”, en BREWER, John and PORTER, Roy (editores) Consumption and the World of Goods, Routledge, London, 1993, pp. 40-57.

COHEN, Lizabeth, A Consumers' Republic: The Politics of Mass Consumption in Postwar America, Vintage Books, Nueva York, 2003.

COSSE, Isabella, Mafalda: historia social y politica, Fondo de Cultura Económica, Buenos Aires, 2010.

DAVIDOFF, Leonore y HALL, Catherine, Family Fortunes: Men and Women of the English Middle Class, Hutchison, London, 1987.

DOUGLAS, Mary y ISHERWOOD, Baron, The world of Goods, Basic Books, Nueva York, 1979. 
ELENA, Eduardo, Dignifying Argentina: Peronism, Citizenship, and Mass Consumption, University of Pittsburgh Press, 2011.

EPP, Marlene, IACOVETTA, Franca y SWYRPA, Frances (editoras) Sisters or Strangers? Immigrant, Ethnic, and Racialized Women in Canadian History, University of Toronto Press, Toronto, 2004.

FERNÁNDEZ, Sandra, La revista EL Círculo o el arte de papel Una experiencia editorial en la Argentina del Centenario, Universidad de Murcia, Murcia, 2010.

GLENNIE, Paul, “Consumption within Historical Studies”, en MILLER, Daniel (editor) Acknowledging Consumption: A Review of Studies, Routledge, London and New York, 1995.

GRIGNON, Claude y PASSERON, Jean-Claude, Lo culto y lo popular. Miserabilismo y populismo en sociología y literatura, Nueva Visión, Buenos Aires, 1991.

HOROWITZ, Daniel, The Morality of Spending: Attitudes toward the Consumer Society in America, 18751940, Johns Hopkins University Press, Baltimore, 1985.

HOROWITZ, Roger y MOHUN, Arwen (editores) His and Hers: Gender, Consumption and Technology, University Press of Virginia, Charlottesville and London, 1998.

KARUSH, Matthew, Cultura de clase. Radio y cine en la creación de una Argentina dividida (1920-1946), Ariel, Buenos Aires, 2013.

LLUCH, Andrea, Las manos visibles del mercado: Intermediarios y consumidores en la Argentina (Siglos XIX y XX), Prohistoria, Rosario, 2015.

MANZANO, Valeria, The Age of Youth in Argentina: Culture, Politics, and Sexuality from Perón to Videla, The University of North Carolina Press, 2014.

MCKENDRICK, Neil, "Home demand and economic growth: a new view of the role of women and children in the industrial revolution", en MCKENDRICK, Neil (editor) Historical Perspectives: Studies in English Thought and Society in Honour of J. H. Plum, Hutchison, London, 1974.

MCKENDRICK, Neil, BREWER, John y PLUMB, John Harold, The Birth of a Consumer Society: The Commercialization of Eighteenth Century England, Hutchison, London, 1982.

MENNELL, Stephen, All Manners of Food: Eating and Taste in England and France from the Middle Ages to the Present, Blackwell, Oxford, 1985.

MILANESIO, Natalia, “The Guardian Angels of the Domestic Economy”: Housewives' Responsible Consumption in Peronist Argentina”, en Journal of Women's History, New York, 2006, V. XVIII, No 3, pp. 91-117.

MILANESIO, Natalia, Cuando los trabajadores salieron de compras: nuevos consumidores, publicidad y cambio cultural durante el primer peronismo, Siglo XXI, Buenos Aires, 2014. 
NARI, Marcela y FEIJÓO, María del Carmen, "Women in Argentina during the 1960's", en Latin American Perspectives, Riverside, 1996, V. 23, No 1, pp. 7-27.

PASTORIZA, Elisa, Mar del Plata, la conformación de una ciudad turística de masas, UNMDP, Mar del Plata, 1993.

PASTORIZA, Elisa (editora) Las puertas al Mar. Consumo, ocio y politica en Mar del Plata, Montevideo y Viña del Mar, Biblos, Buenos Aires, 2002.

PÉREZ, Inés, El hogar tecnificado: familias, género y vida cotidiana, Biblos, Buenos Aires, 2012.

PÉREZ, Inés y RIBEIRO DOS SANTOS, Marinês (editoras) Gênero e consumo: representaçôes midiáticas de práticas de consumo no espaço doméstico (Argentina e Brasil no Século XX), UFPR Editora, Curitiba, (en prensa).

PIGLIA, Melina, "En torno a los Parques Nacionales: primeras experiencias de una política turística nacional centralizada en la Argentina (1934-1950)", en PASOS, Revista de Turismo y Patrimonio, Santa Cruz de Tenerife, 2012, V. 10, No 1, pp. 61-73.

PIGLIA, Melina, "El ACA e YPF entre las administraciones conservadoras y el peronismo. La red nacional de estaciones de servicio", en Boletín del Instituto de Historia Argentina y Americana "Dr. Emilio Ravignani”, Tercera Serie, Buenos Aires, 2013, No 37, pp. 143-173.

PIGLIA, Melina, Autos, rutas y turismo: el automóvil club argentino y el estado, Siglo XXI, Buenos Aires, 2014.

PIGLIA, Melina, "Commercial Aviation in Argentina: A Call to Re-think the History of Aeromobility in Latin America”, en T2M Yearbook 2015, (en prensa).

PITE, Rebekah, Creating a common table in twentieth-century Argentina: Doña Petrona, Women and Food, The University of North Carolina Press, 2013.

PUJOL, Sergio, La década rebelde. Los años 60 en la Argentina, Emecé, Buenos Aires2002; GAYOL, Sandra y MADERO, Marta (editoras) Formas de Historia Cultural. Prometeo, Buenos Aires, 2007.

PULJU, Rebecca, "Consumers for the Nation: Women, Politics, and Consumer Organization in France, 1944-1965”, en Journal of Women’s History, New York, 2006. V. XVIII, No 3, pp. 68-90.

REMEDI, Fernando, Dime qué comes y cómo lo comes y te diré quién eres. Una historia social del consumo alimenario en la modernización argentina. Córdoba, 1870-1930, Centro de Estudios Históricos "Prof. Carlos S. A. Segreti”, Córdoba, 2006.

RITZER, George y SLATER, Don, "Editorial”, en Journal of Consumer Culture, V. 1, No 1, 2001, pp. 5-8.

ROCCHI, Fernando, "Consumir es un placer: la industria y la expansión de la demanda en Buenos Aires a la vuelta del siglo pasado”, en Desarrollo Económico, V. 37, No 148, 1998, pp. 533-558.

ROCCHI, Fernando, "Inventando la soberanía del consumidor: publicidad, privacidad y revolución del 
mercado en la Argentina (1860-1940)", en DEVOTO, Fernando y MADERO, Marta (compiladores) Historia de la vida privada en la Argentina, Taurus, Buenos Aires, 1999, pp. 201-322.

ROCCHI, Fernando, "La americanización del consumo: las batallas por el mercado argentino, 1920-1945”, en BARBERO, María Inés. y REGALSKY, Andrés (editores) Estados Unidos y América Latina en el siglo XX. Transferencias económicas, tecnológicas y culturales, UNTREF, Buenos Aires, 2003, pp. 131-189.

ROCCHI, Fernando, Chimneys in the Desert. Industrialization in Argentina during the Export Boom Years, 1870-1930, Stanford University Press, 2006.

SCANLON, Jennifer, Inarticulate Longings: The Ladies' Home Journal, Gender and the Promises of Consumer Culture, Routledge, Londres y Nueva York, 1995.

SCANLON, Jennifer (editora) The Gender and Consumer Culture Reader, New York University Press, Nueva York y Londres, 2000.

SHAMMAS, Carole, "Changes in English and Anglo-American consumption from 1550-1800", en BREWER, John y PORTER, Roy (editores) Consumption and the World of Goods, Routledge, London, 1993, pp. 177-205.

SMART, Judith, "The Politics of Consumption: The Housewives' Associations in South-eastern Australia Before 1950”, en Journal of Women's History, New York, 2006, V. XVIII, No 3, pp. 13-39.

STORRS, Landon, "Left-Feminism, the Consumer Movement, and Red Scare Politics in the United States, 1935-1960”, en Journal of Women's History, New York, 2006, V. XVIII, No 3, pp. 40-67.

STRASSER, Susan, "Making Consumption Conspicuous: Transgressive Topics Go Mainstream", en Technology and Culture, Baltimore, 2002, V. 43, No 4, pp. 755-770.

TORRE, Juan Carlos y PASTORIZA, Elisa, "Mar del Plata el sueño de los argentinos", en DEVOTO, Fernando y MADERO, Marta (compiladores) Historia de la vida privada en la Argentina. La Argentina entre multitudes y soledades, de los años treinta a la actualidad. Buenos Aires, Taurus T. III, 1999, pp. 49-77.

TORRE, Juan Carlos y PASTORIZA, Elisa, “La democratización del bienestar", en Juan Carlos Torre (compilador) Los años peronistas, Sudamericana, Buenos Aires, 2002, pp. 257-312. 